Supporting Information for

\title{
A New Group of Edge-Transitive 3-Periodic Nets and Their Derived Nets for Reticular Chemistry
}

Mian Li, ${ }^{*} \dagger$ Michael O’Keeffe, ${ }^{*},+$ Davide M. Proserpio,,$\stackrel{\S}{,}$ and Hai-Feng Zhang ${ }^{\dagger}$

${ }^{\dagger}$ Department of Chemistry and Key Laboratory for Preparation and Application of Ordered Structural Materials of Guangdong Province, Shantou University, Guangdong 515063, P. R. China. *E-mail: mli@stu.edu.cn

${ }^{+}$School of Molecular Sciences, Arizona State University, Tempe, AZ 85287, United States. *Email: mokeeffe@asu.edu

${ }_{\S}^{\S}$ Dipartimento di Chimica, Università degli studi di Milano, 20133 Milano, Italy.

"Samara Center for Theoretical Material Science (SCTMS), Samara State Technical University, 443100 Samara, Russia. 
Table S1. Some derived 22 nets obtained from new edge-transitive nets

\begin{tabular}{llll}
\hline Edge-transitive net & $\mathrm{CN}^{\mathrm{a}}\left(\mathrm{VF}^{\mathrm{b}}\right)$ & Derived 2 2 net & $\mathrm{CN}^{\mathrm{a}}\left(\mathrm{VF}^{\mathrm{b}}\right)$ \\
\hline cyc & $4,8(\mathrm{~S}, \mathrm{C})$ & $\mathbf{c x c}$ & $3,8(3, \mathrm{C})$ \\
& & cwc & $3,8(3, \mathrm{C})$ \\
\hline $\mathbf{d f s}$ & $4,12(\mathrm{~S}, \mathrm{X})$ & $\mathbf{d f x}$ & $3,12(3, \mathrm{X})$ \\
& & $\mathbf{d f w}$ & $3,12(3, \mathrm{X})$ \\
\hline $\mathbf{c y g}$ & $4,16(\mathrm{~S}, \mathrm{G})$ & $\mathbf{c v g}$ & $3,16(3, \mathrm{G})$ \\
& & $\mathbf{c w g}$ & $3,16(3, \mathrm{G})$ \\
\hline $\mathbf{h f z}$ & $4,24(\mathrm{~S}, \mathrm{M})$ & $\mathbf{h f v}$ & $3,24(3, \mathrm{M})$ \\
& & $\mathbf{h f w}$ & $3,24(3, \mathrm{M})$ \\
\hline $\mathbf{c y f}$ & $4,24(\mathrm{~S}, \mathrm{~W})$ & $\mathbf{c x f}$ & $3,24(3, \mathrm{~W})$ \\
\hline
\end{tabular}

${ }^{\mathrm{a}} \mathrm{CN}=$ coordination number. ${ }^{\mathrm{b}} \mathrm{VF}=$ vertex figure, for which $3=$ triangle, $\mathrm{S}=$ square, $\mathrm{C}=$ cube, $\mathrm{X}=$ hexagonal prism, $\mathrm{G}=$ octagonal prism, $\mathrm{M}=$ dodecagonal prism, $\mathrm{W}=$ truncated cube.

Table S2. Occurrences and names of derived 22 nets here reported

\begin{tabular}{|c|c|c|l|l|}
\hline $\begin{array}{c}\text { Occurrences in } \\
\text { topcryst.com } \\
\text { (Jan 2020) standard }\end{array}$ & $\begin{array}{c}\text { Occurrences in } \\
\text { topcryst.com } \\
\text { (Jan 2020) cluster }\end{array}$ & $\begin{array}{c}\text { RCSR } \\
\text { name }\end{array}$ & SPGR $^{\text {a }}$ & $\begin{array}{l}\text { ToposPro } \\
\text { name(s) }\end{array}$ \\
\hline \multicolumn{5}{|c|}{ DERIVED NETS - NC - transitivity 2 2 } \\
\hline- & - & dfx & $P 6 / m m m$ & NEW \\
\hline- & - & dfw & $P 6 / m m m$ & NEW \\
\hline- & - & cxc & $P 42 / m m c$ & NEW \\
\hline- & $3(2-\text { fold) })^{b}$ & cwc & $P 42 / m m c$ & $3,8 T 55$ \\
\hline- & - & cvg & $P 4 / m m m$ & NEW \\
\hline- & - & cwg & $P 4 / m m m$ & NEW \\
\hline- & - & hfv & $P 6 / m m m$ & NEW \\
\hline- & - & hfw & $P 6 / m m m$ & NEW \\
\hline- & - & cxf & $P m \overline{3}$ & NEW \\
\hline
\end{tabular}

${ }^{\mathrm{a}} \mathrm{SPRG}=$ space group. ${ }^{\mathrm{b}}$ CCDC refcodes: EFESEP, EFESIT, EFESOZ (2-fold interpenetrated isomorphous structures). 


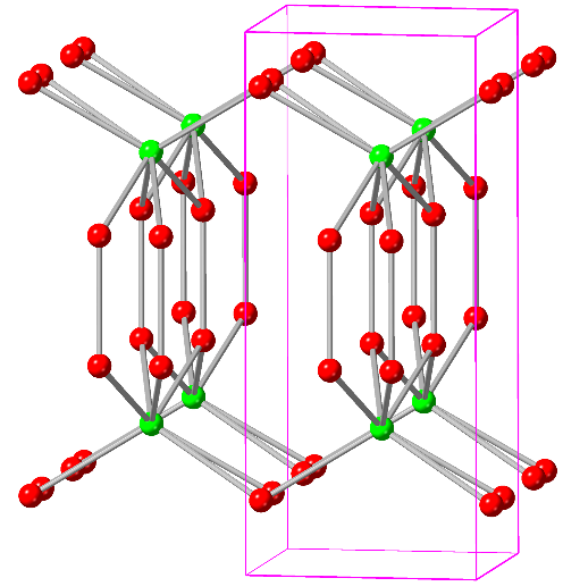

CXC

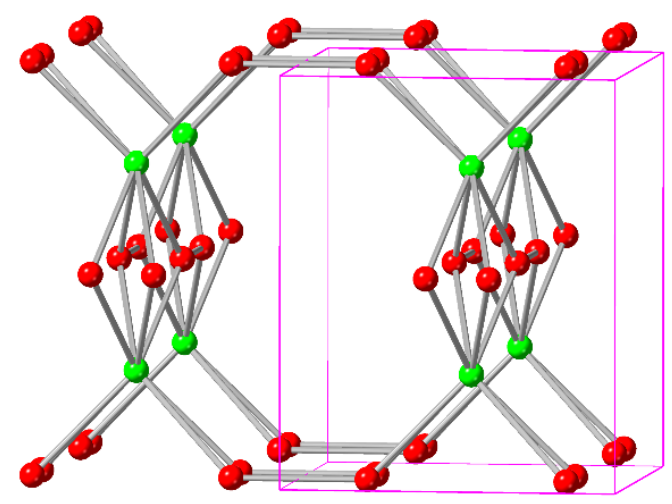

CWC

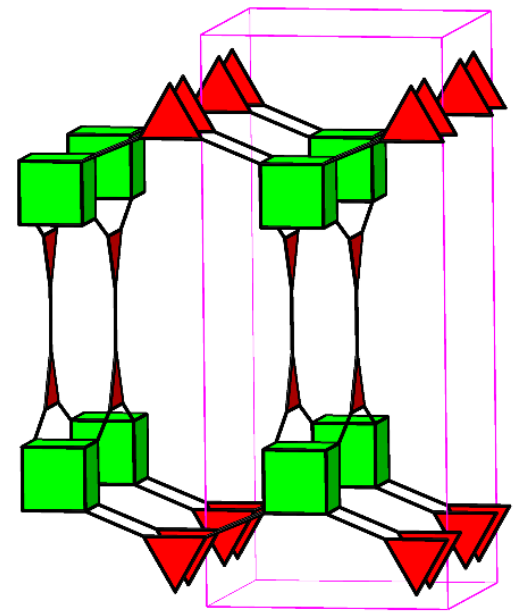

cxc-a

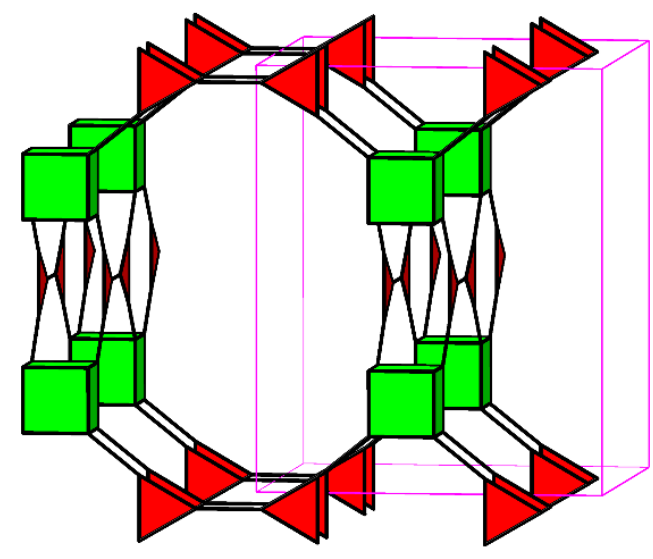

cWC-a

Figure S1. cyc-derived nets with minimal transitivity 22 (left) and their augmented nets (right). 


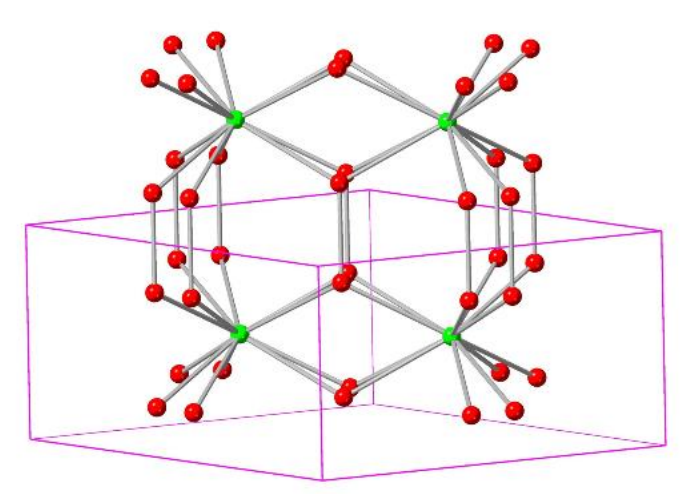

$d f x$

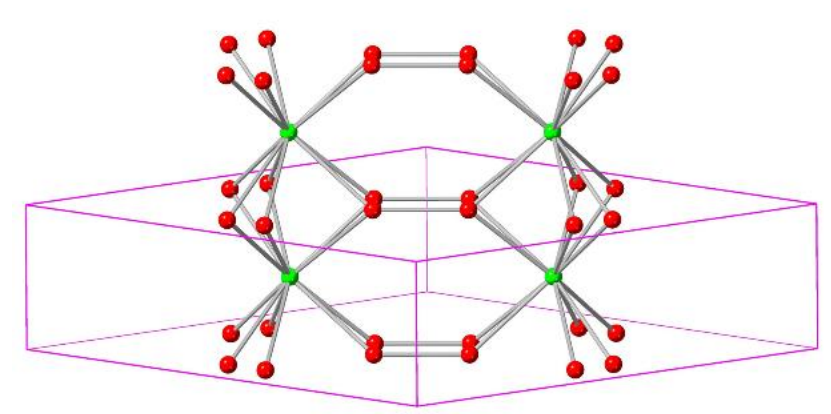

dfw

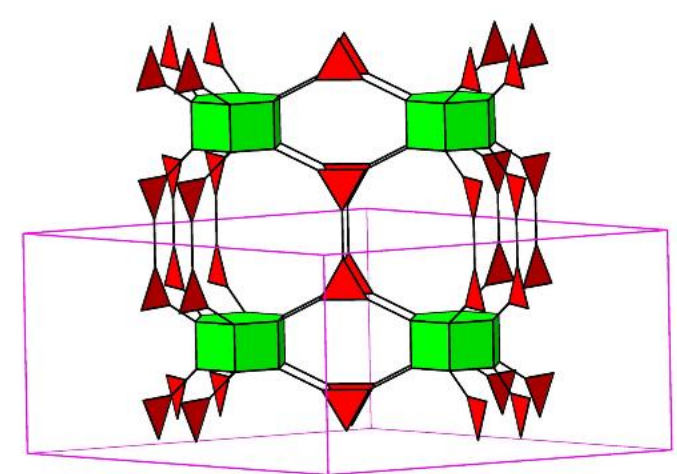

$d f x-a$

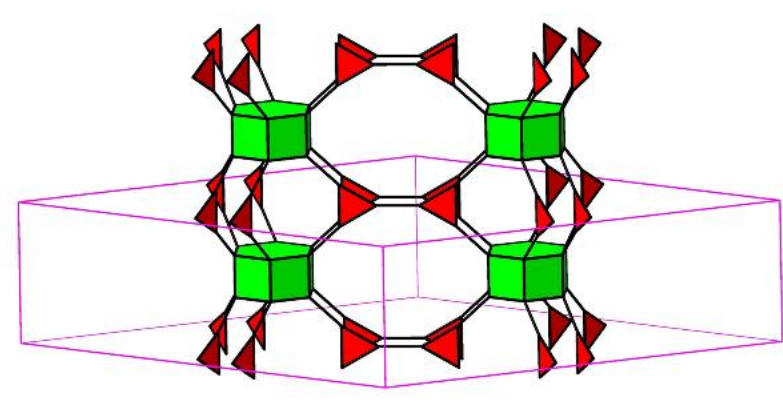

dfw-a

Figure S2. dfs-derived nets with minimal transitivity 22 (left) and their augmented nets (right). 


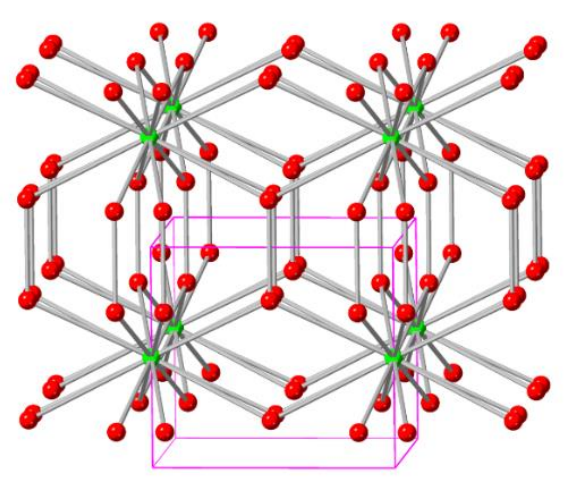

CVg

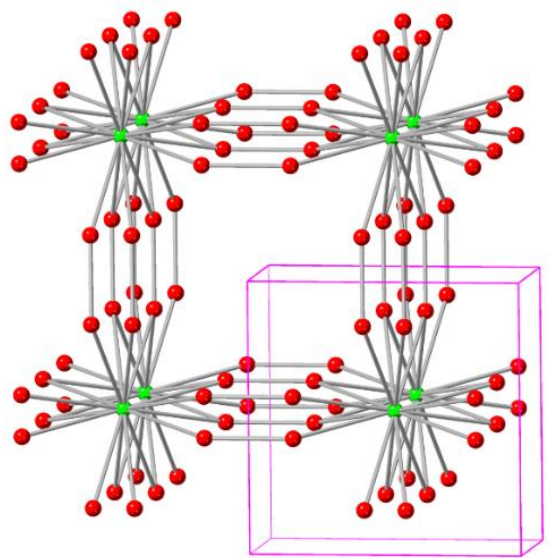

CWg

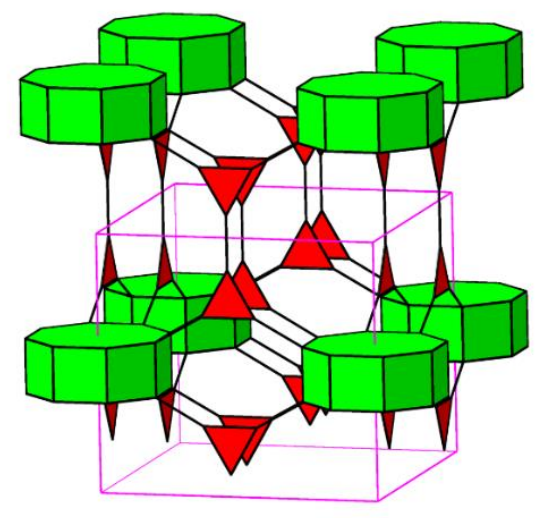

cvg-a

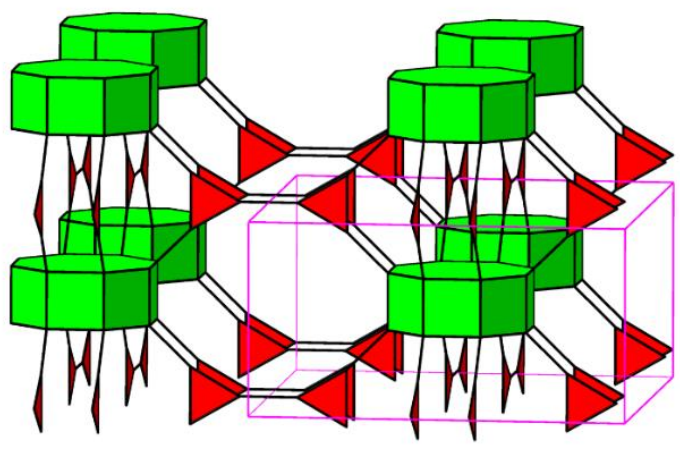

cwg-a

Figure S3. cyg-derived nets with minimal transitivity 22 (left) and their augmented nets (right). 


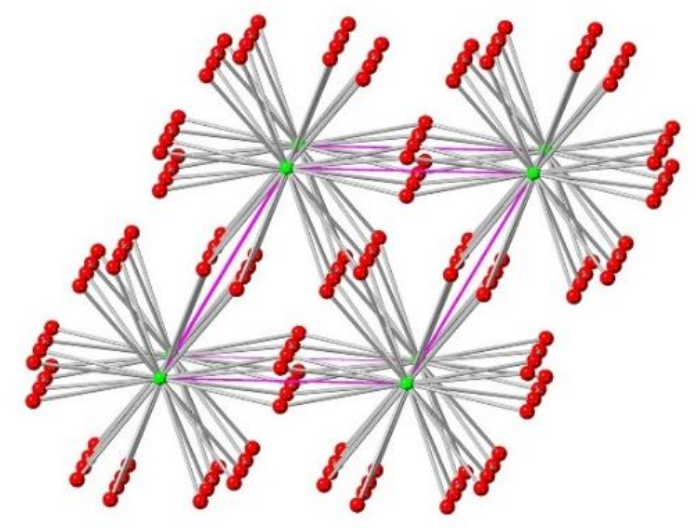

hfv

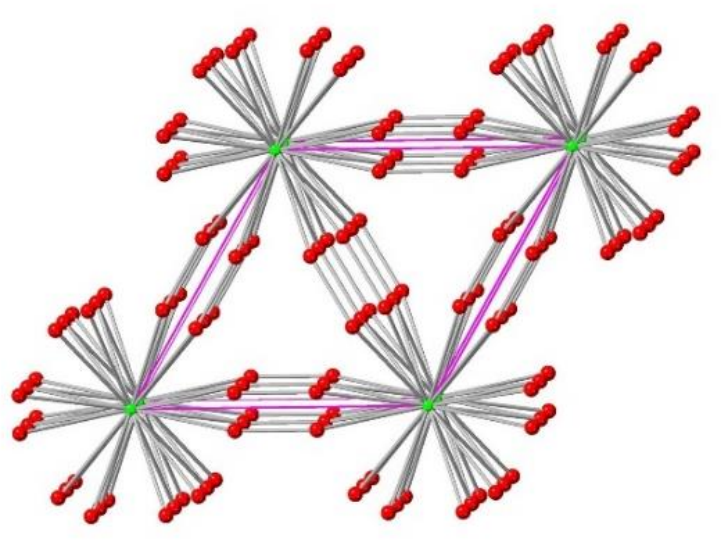

hfw

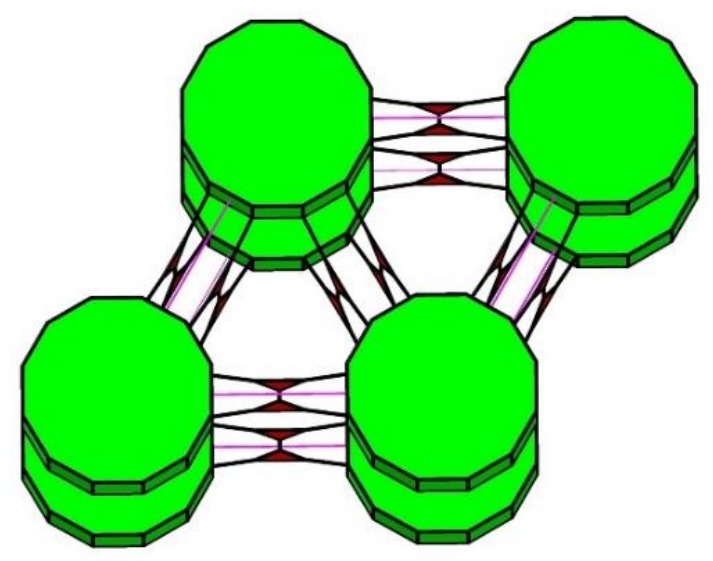

hfv-a

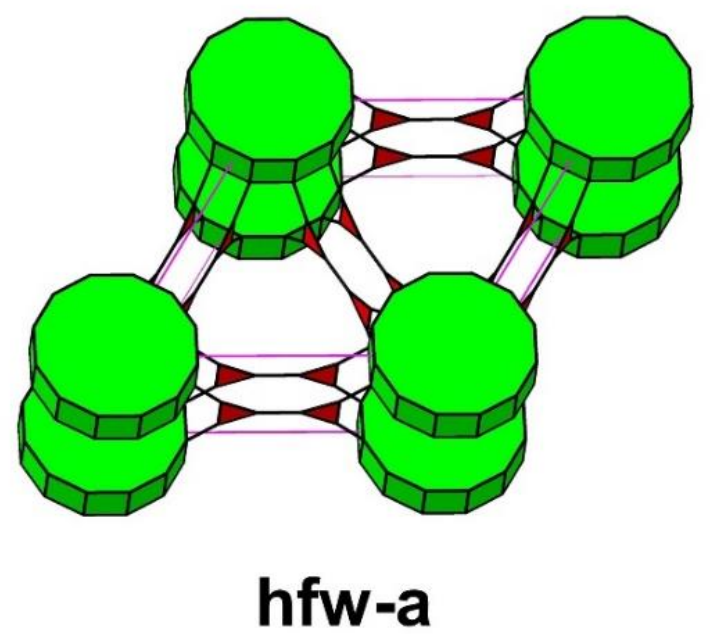

Figure S4. hfz-derived nets with minimal transitivity 22 (left) and their augmented nets (right). 

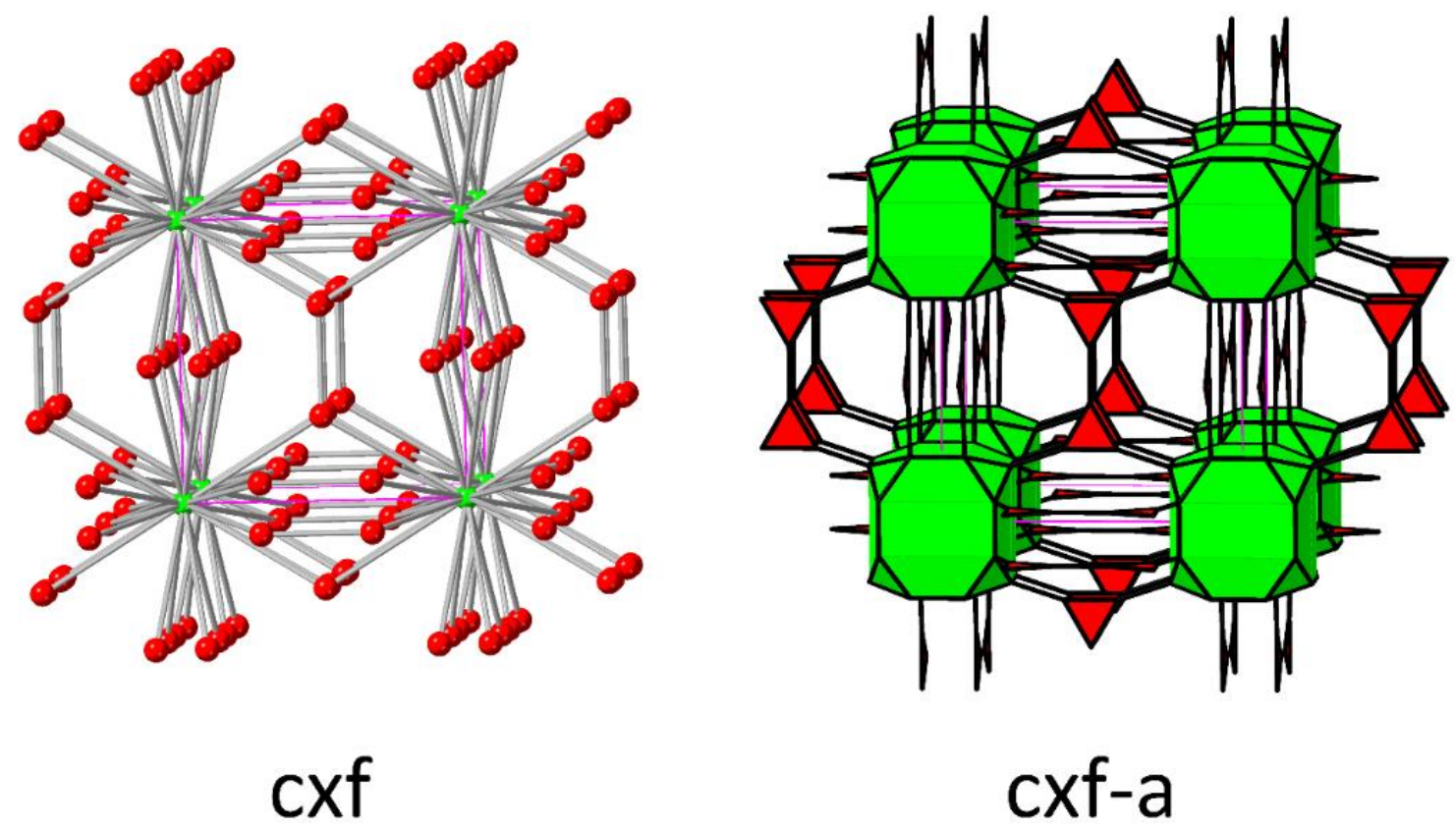

Figure S5. cyf-derived net with minimal transitivity 22 (left) and its augmented net (right). Note that the symmetry of the derived net $\mathbf{e x f}(P m \overline{3})$ is lower than that of $\mathbf{c y f}(P m \overline{3} m)$. 

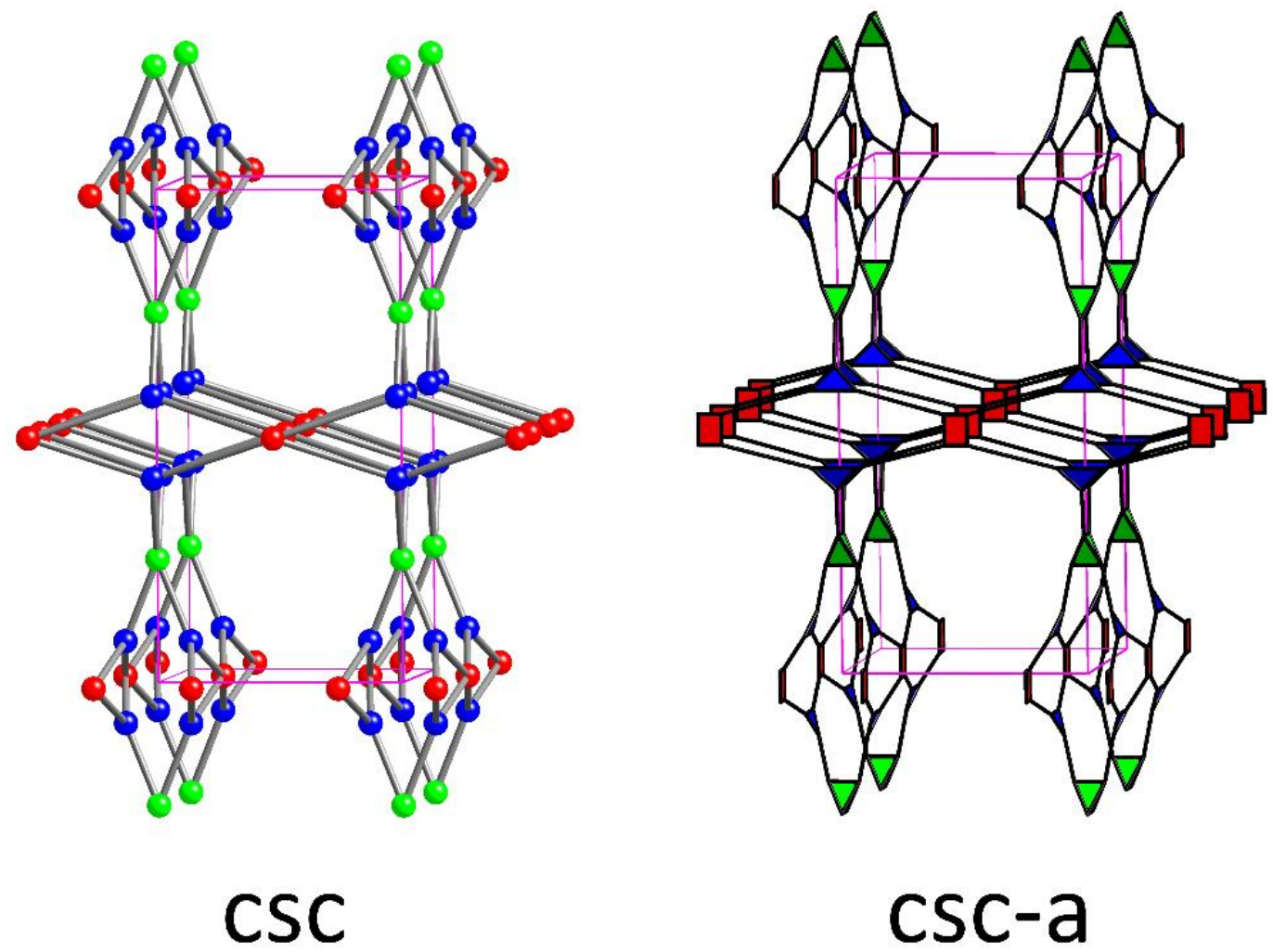

Figure S6. cyc-derived net with minimal transitivity 32 (left) and its augmented net (right). Note that both nets are non-crystallographic. 


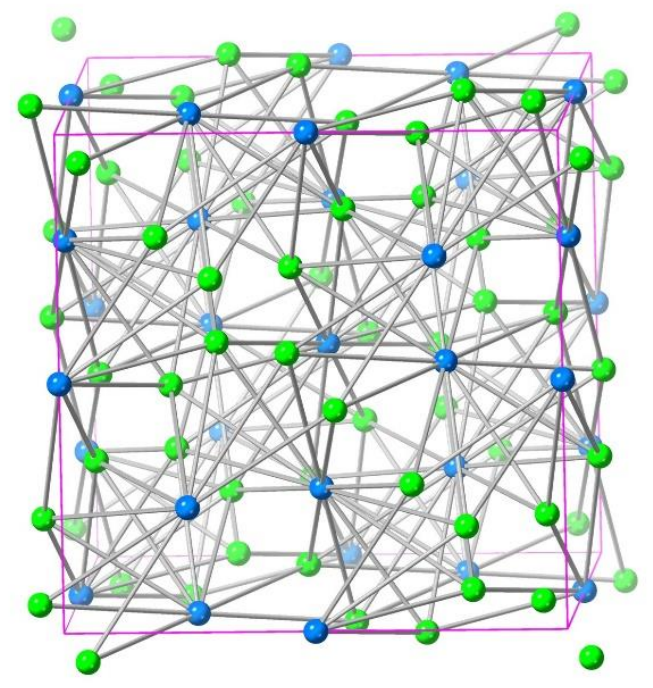

cyu

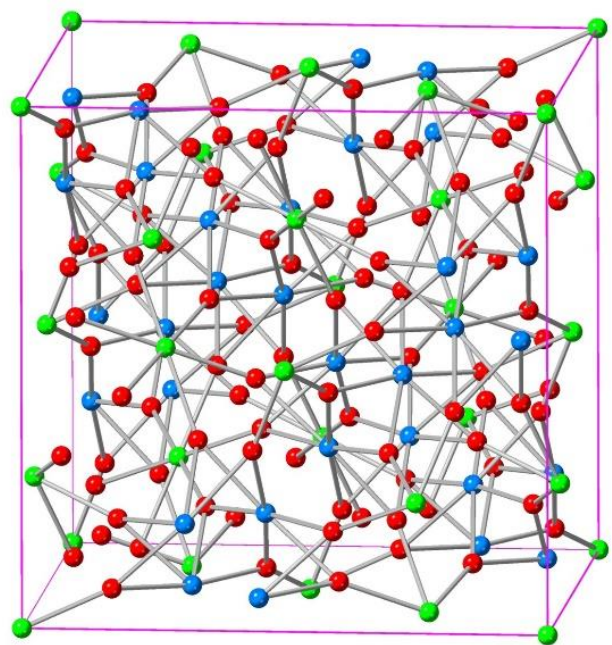

\section{hxh}

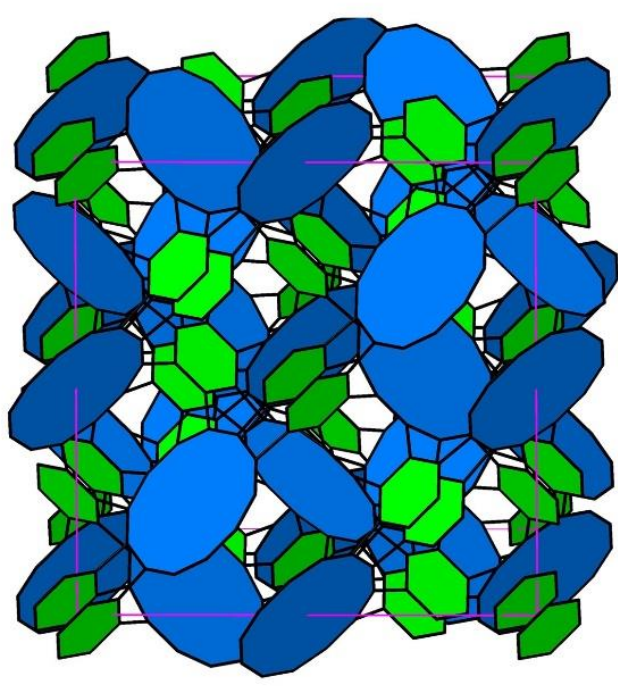

cyu-a

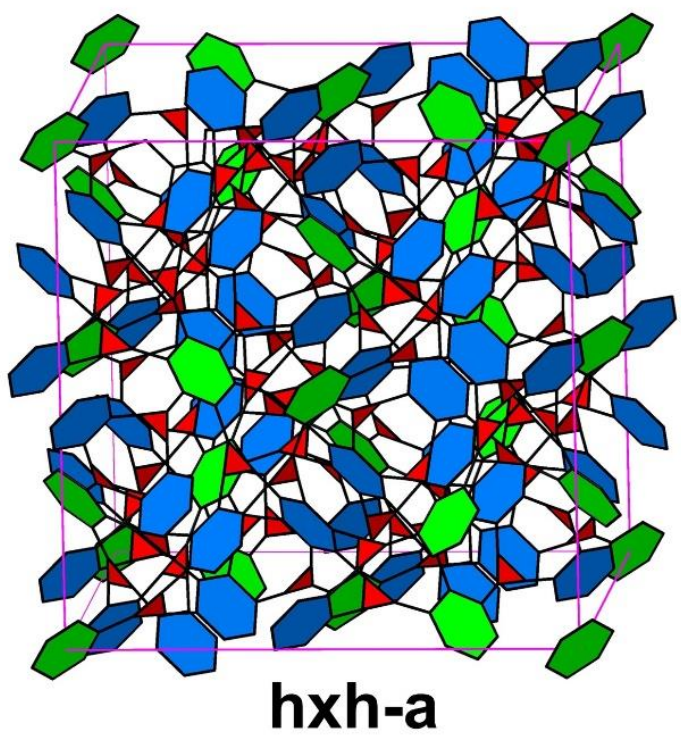

Figure S7. cyu and its derived 32 net $\mathbf{h x h}$ (left), as well as their augmented net (right), showing the dense arrangement of nodes in contrast to other nets in this work. 

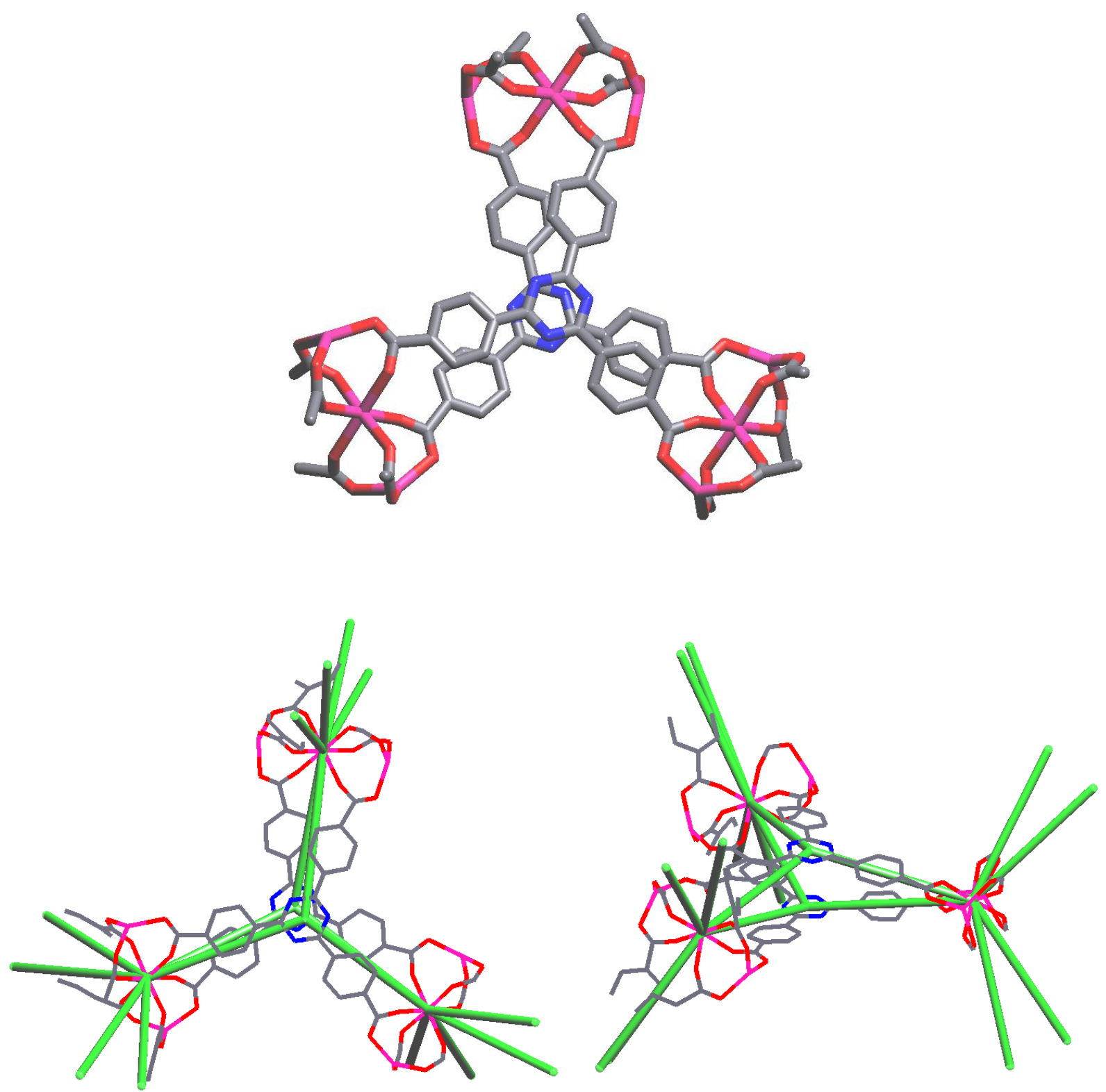

Figure S8. The underlying nets $(3,6)$-c cys observed in 9 structures with the "all node" - ToposPro cluster representation. All the structures presents a similar eclipsed arrangement of tritopic ligands linked to trimeric SBU. 